\title{
Lab
}

Arquivos de Ciências do Mar

\section{O SOCIAL COMO PRIORIDADE NA PESGA ARTESANAL: DIRETRIZES INTERNAGIONAIS PARA A PESGA ARTESANAL SUSTENTÁVEL}

\author{
Social as a priority in small scale fishery: \\ international guidelines for sustainable artisanal fisheries
}

\author{
Beatriz Mesquita Jardim Pedrosa1, Rosangela Paula Teixeira Lessa² \\ ${ }^{1}$ Fundação Joaquim Nabuco (FUNDAJ), Coordenação de Estudos Ambientais e da Amazônia, \\ R. Dois Irmãos, 92, Apipucos, Recife-PE, CEP 52071-440, Brazil \\ 2 Laboratório de Dinâmica de Populações Marinhas (DIMAR), Departamento de Pesca e Aquicultura (DEPAq), \\ Universidade Federal Rural de Pernambuco (UFRPE), R. Dom Manoel de Medeiros, S/N \\ Dois Irmãos, Recife-PE, CEP 52171 - 900, Brazil rptlessa@gmail.com
}

\begin{abstract}
RESUMO
As Diretrizes Voluntárias para assegurar a Pesca artesanal sustentável no contexto da Segurança Alimentar e Erradicação da Pobreza (Diretrizes da Pesca Artesanal) foram aprovadas em 2014 no âmbito da Organização das Nações Unidas para a Agricultura e Alimentação (FAO). Este artigo discute seu processo de criação e analisa os principais temas de conflito e mudanças ocorridas durante as consultas técnicas de elaboração do texto, realizadas pela FAO. As diretrizes da pesca mostram que a pesca artesanal envolve a interdisciplinaridade e exige governança em: garantia ao território, saúde, educação, segurança do trabalho e resolução de conflitos com outras atividades estão além da gestão da própria atividade pesqueira.
\end{abstract}

Palavras-chave: FAO, pesca artesanal, documentos internacionais, governança.

\section{ABSTRACT}

The Voluntary Guidelines for Securing Sustainable Small Scale Fisheries in the context of Food Security and Poverty Eradication (SSF Guidelines) were approved in 2014 under the United Nations Food and Agriculture Organization (FAO) scope. This article discusses the process and

Recebido em: 26/4/2017

Aprovado em: 18/7/2017

Publicado online em: 20/1/2018 
analyzes the main conflicts and changes during the FAO technical consultations. The SSF Guidelines show that artisanal fishery involves interdisciplinarity and requires governance in the following themes: ensuring the territory, health, education, safety and conflict resolution with other activities, themes that are beyond the own fishing activity management.

Key-words: FAO, small-scale fisheries, international documents, governance.

\section{INTRODUÇÃO}

O papel da pesca artesanal representa para a seguridade alimentar e mitigação da pobreza no mundo foi reconhecido no dia 13 de Junho de 2014, na 31. ${ }^{\circ}$ Sessão do Comitê de Pesca (COFI) da Organização das Nações Unidas para a Agricultura e Alimentação (FAO) com a adoção por 143 países membros das Diretrizes Voluntárias para assegurar a Pesca de Pequena Escala (PPE) sustentável no contexto da Segurança Alimentar e Erradicação da Pobreza a que chamaremos de "Diretrizes da Pesca Artesanal" ou "Diretrizes", documento que trata de sustentabilidade e desenvolvimento social na pesca artesanal em uma perspectiva de direitos humanos (FAO, 2015a).

A sustentabilidade da pesca artesanal é vista como a capacidade dos recursos naturais e sua exploração perdurarem além do curto prazo, considerando variáveis socioeconômicas, culturais e políticas como co-responsáveis pelo sucesso ou não de um processo produtivo. A integração dessas variáveis compõe o cerne da sustentabilidade. O conceito ressalta a importância de questões como igualdade, justiça e direitos humanos e incentivou uma visão cultural e construtivista da relação ambiente-sociedade.

A demanda por um documento que complementasse o Código de Conduta para a Pesca Responsável (1995), cujo enfoque são as questões ambientais e pesca industrial, foi consolidada em Conferência Mundial Sobre a Pesca de Pequena Escala realizada em Bangkok (Tailândia), em 2008, e seus resultados apresentados nas Diretrizes, em 2014.

A pesca artesanal é responsável por mais da metade das capturas globais. O setor emprega diretamente mais de $90 \%$ dos quase 38 milhões de pescadores(as) no mundo (FAO, 2016), dos quais 19\% são mulheres, número que aumenta para $50 \%$ ao considerar aquelas envolvidas na cadeia produtiva. Na Ásia e África $60 \%$ dos recursos pesqueiros são comercializados por mulheres (FAO, 2015b).

Historicamente, a pesca artesanal foi abordada secundariamente nas sociedades e políticas públicas, como visualizado em atributos negativos utilizados no âmbito da FAO, em 1972 (Mathew, 2014). Utilizava-se termos como: baixo investimento de capital, baixo nível de organização, pouco uso de habilidades especializadas, barcos pequenos, artes de pesca manuais, baixa produtividade e renda, infraestrutura e crédito inadequados e captura comercializada in natura, salgada, seca ou defumada em mercados locais. As Diretrizes recentemente aprovadas, por sua vez, reconhecem o papel dos pescadores(as) artesanais e dos serviços por eles prestados como um subsetor diversificado e dinâmico, muitas vezes caracterizado por migrações sazonais, ancorada em comunidades locais, refletindo ligações históricas com recursos pesqueiros adjacentes, tradições e valores, apoiando a coesão social.

O texto a seguir foi elaborado com o objetivo de analisar e divulgar o conteúdo e o processo de elaboração das "Diretrizes da Pesca Artesanal", bem como estimular sua 
adoção no Brasil por atores envolvidos na pesca artesanal: pescadores(as), pesquisadores, governo, setor empresarial e consumidores.

\section{A ELABORAÇÃO DAS DIRETRIZES}

Sua elaboração foi aprovada pelos representantes dos governos na FAO, em 2011, após uma série de consultas regionais que identificaram a necessidade de se garantir o desenvolvimento social, cultural e econômico das comunidades e os direitos de acesso e uso sustentável de recursos. A relação com a sociedade civil desde a década de 1990 se concretiza, passando de consultas aos atores da pesca esparsas, como no Código de Conduta para a Pesca Responsável (FAO, 1995), para protagonistas e responsáveis por consultas globais nas Diretrizes (Trapman, 2014).

$\mathrm{O}$ "processo de consulta à sociedade civil" foi realizado por meio de organizações internacionais representativas dos pescadores e organizações de apoio tais como: o Fórum Mundial de Povos Pescadores (WFFP), o Fórum Mundial de Pescadores e Trabalhadores da Pesca (WFF), o Coletivo Internacional de Apoio aos Pescadores Artesanais (ICSF), e o Comitê Internacional de Planejamento das ONG/OSC para a Soberania Alimentar (IPC), totalizando mais de 300 milhões de pequenos produtores de alimentos. Essa coalizão elaborou uma carta inicial de comprometimento e apoio.

A sociedade civil promoveu consultas nacionais em todas as regiões do mundo, para a elaboração de um documento único denominado de "Rascunho Zero da Sociedade Civil". Os documentos nacionais tinham o objetivo de propor diretrizes e nortear a atuação nacional na internalização do documento. Foram realizados seminários que reuniram 37 países. A metodologia para a construção dos documentos nacionais foi uniforme e participativa reunindo mais de 2.300 pessoas que elaboraram 15 documentos básicos para a proposta da sociedade civil. A primeira versão do "Rascunho Zero da Sociedade Civil” foi elaborada por equipe da África do Sul, mas outros documentos foram gerados pela FAO. De posse de todas as propostas, a FAO elaborou seu próprio “Rascunho Zero". Finalmente, os países membros entraram em consenso e o documento final foi adotado em junho de 2014.

Na primeira consulta técnica (67 países), muitas delegações não tinham familiaridade com o conteúdo interdisciplinar do texto, apenas $60 \%$ do texto foi analisado. Questões controversas foram deixadas para uma segunda etapa. Algumas delegações afirmavam não poder decidir em matérias adversas à pesca como saúde e educação, por exemplo. Já na segunda consulta, os 97 países participantes trouxeram posicionamentos bem definidos. Países africanos junto com a Noruega, Brasil, Filipinas, Indonésia, Equador e Bangladesh compuseram um bloco defensor das propostas inseridas no documento (rascunho zero), enquanto o Canadá, Argentina, Chile, Estados Unidos e União Européia apresentaram resistência ao seu conteúdo.

Além dos governos, participavam como observadores com direito a voz membros da sociedade civil, organizações intergovernamentais, ONGs internacionais como a UICN, Comissão de Direitos Humanos das Nações Unidas e pesquisadores.

No Brasil, foi realizada consulta à representantes dos pescadores(as) artesanais e de instituições de apoio, em Novembro de 2011, na comunidade pesqueira da Prainha do Canto Verde, Ceará, coordenada pelo ICSF e Instituto Terramar. No último dia as propostas foram apresentadas a representantes do governo.

Participaram desse seminário representantes de pescadores e pescadoras, pesquisadores e os membros do ICSF Brasil, além dos representantes do governo federal, estadual 
e municipal que estiveram presentes no último dia. O Brasil também participou de uma consulta realizada pela FAO a pesquisadores. Não houve qualquer outra consulta nacional por parte do Ministério da Pesca ou Ministério das Relações Exteriores, ambos participantes das consultas técnicas.

\section{CONTEÚDO DO DOCUMENTO E POSICIONAMENTO DOS ESTADOS MEMBRO}

Os direitos humanos (Song, 2015) como cerne das Diretrizes traz um novo conceito para a abordagem da pesca artesanal, ampliam os horizontes da governança do setor e atribuem aos pescadores(as) papel central na atividade.

As Diretrizes complementam instrumentos internacionais importantes como o Código de Conduta da Pesca Responsável, as Diretrizes Técnicas para Pesca Responsável n. ${ }^{\circ} 10$ "Aumentar a Contribuição da Pesca de Pequena Escala para Combate a Pobreza e Segurança Alimentar", as Diretrizes Voluntárias sobre a Governança Responsável da Posse da Terra, Pesca e Florestas no Contexto da Segurança Alimentar Nacional e as Diretrizes Voluntárias em apoio à realização progressiva do direito à Alimentação Adequada no Contexto da Segurança Alimentar Nacional (Diretrizes de Direito Alimentar).

O documento enfatiza a natureza do direito coletivo, questões de gênero e a importância das mulheres para a atividade, cultura, contribuição à segurança alimentar mundial, à nutrição e à erradicação da pobreza. Além disso, mostra a necessidade de proteção em relação à segurança de trabalho, a degradação ambiental e atividades impactantes, mudanças climáticas e desastres naturais.

As propostas são divididas em Direitos de acesso, governança e manejo de recursos; Desenvolvimento social, emprego e trabalho decente; Cadeia produtiva, pós-colheita e mercado; Igualdade de gênero; Riscos de desastres e mudança climática; Coerência política, coordenação e colaboração institucional; Informação, pesquisa e comunicação; Capacitação e Apoio a implementação e monitoramento.

A dificuldade de definição uniforme sobre pesca artesanal foi consenso desde as consultas nacionais. Sua natureza diversa não permite que exista definição única, devendo esta ser realizada por cada país. Em alguns casos, como o Brasil, é difícil uma única definição, explicitada na consulta Brasil realizada pela sociedade civil:

Entende-se que a pesca artesanal no Brasil assume configurações específicas de acordo com as diversas regiões do país, desde a Amazônia onde é realizada para subsistência em sua maioria até a região Sul do Brasil onde assume configuração mais comercial, tanto nas águas marítimas quanto nas interiores. A definição no Brasil merece ser regionalizada, tanto para efeito de entendimento quanto para efeito das políticas públicas.

Atualmente a definição de pesca artesanal no Brasil é dada pela Lei da Pesca (Lei 11.959/2009) como: “... quando praticada diretamente por pescador profissional, de forma autônoma ou em regime de economia familiar, com meios de produção próprios ou mediante contrato de parceria, desembarcado, podendo utilizar embarcações de pequeno porte (até 20 TBA)".

Mais ainda, deve-se entender que a pesca artesanal é um sistema que sofre influência de outras atividades econômicas e conectado a contextos sociais e culturais complexos, não devendo ser tratada isoladamente (Jentoft, 2014). Sobre isso o texto das 
Diretrizes afirma que a pesca artesanal sofre com as relações desiguais de poder em relação a outros setores: turismo, aquicultura, agricultura, energia, mineração, indústria e o desenvolvimento de infra-estruturas.

Outro consenso entre os estados foi a natureza voluntária das Diretrizes. Conceitos controversos como o termo governança e padrões de direitos humanos foram substituídos por manejo pesqueiro e leis de direitos humanos, por exemplo. Por outro lado, o processo participativo e legítimo de elaboração do documento fortalece a importância de sua implementação.

A natureza do direito coletivo é explícita no texto, traduzida em termos citados ao longo de todo o documento: comunidades, cultura, práticas e direitos costumeiros, povos. Outros conceitos como governança, co-manejo, setor informal, e padrões de direitos humanos encontraram resistência, foram enfraquecidos pela plenária, porém continuam a mostrar a necessidade da abordagem coletiva na pesca artesanal.

As questões de gênero na pesca artesanal foram concretizadas pois o documento possui uma seção específica de gênero além do assunto ser transversal nas outras seções, ainda com reação contrária de alguns países.

A soberania nacional é o cerne dos posicionamentos e encontra-se representada na inserção do termo "quando apropriado", sete vezes, em vários parágrafos, abrindo oportunidade para posicionamentos unilaterais. Os principais pontos da negociação, citações nos documentos prévios, bem como naquele aprovado e o posicionamento dos países são apresentados na Tabela 1.

As principais causas de conflito foram acrescentadas não pelo rascunho zero e sim no momento das consultas técnicas, por iniciativas da sociedade civil (necessidade de consentimento em estudos de impacto em atividades prejudiciais à pesca artesanal e situações de ocupação). Os temas que acompanharam todo o processo de discussão estavam bem consolidados e foram mais facilmente consensuados. Na consolidação do rascunho zero da FAO (inputs de governos e outras consultas) foram também acrescentados novos temas como as questões relativas à certificação ambiental e à Organização Mundial de Comércio (OMC), as quais também geraram conflitos nas consultas técnicas.

Questões ambientais foram fortalecidas pelos estados no documento final. Termos como gestão pesqueira e ecossistêmica foram acrescentados como estratégia, em alguns momentos, de diminuir a abordagem de direitos humanos que exige prioridade para as comunidades e ampla participação na elaboração e controle de políticas. Com isso, as Diretrizes se aproximaram do Código de Conduta para a Pesca Responsável (FAO, 1995) e assumiram as fronteiras que a atividade pesqueira enfrenta quando se observa as diversas variáveis ambientais, sendo a sobrepesca e a consequente diminuição dos recursos pesqueiros sua principal limitação. 
Tabela 1 - Principais termos e assuntos sujeitos a restrições durante as consultas técnicas das Diretrizes Voluntárias para assegurar a Pesca de Pequena Escala sustentável no contexto da Segurança Alimentar e Erradicação da Pobreza

\begin{tabular}{|c|c|c|c|c|}
\hline \multirow[b]{2}{*}{$\begin{array}{l}\text { Termo/ } \\
\text { definição }\end{array}$} & \multicolumn{3}{|c|}{ Citações } & \multirow[b]{2}{*}{ Descrição } \\
\hline & $\begin{array}{c}\text { Rascunho } \\
\text { sociedade civil }\end{array}$ & $\begin{array}{l}\text { Rascunho } \\
\text { FAO }\end{array}$ & $\begin{array}{c}\text { Documento } \\
\text { Aprovado }\end{array}$ & \\
\hline
\end{tabular}

Este termo apesar de bem aceito na comunidade científica (Kooiman \& Bavinck 2005, Jentoft \& Chuenpagdee 2009) significando relações que extrapolam o papel do governo, inclui todas as interações públicas e privadas que são iniciadas para $\begin{array}{lllll}\text { Governança } & 41 & 30 & 15 & \text { resolver problemas e criar oportunidades na }\end{array}$ sociedade. A horizontalidade de poder é vista por muitos países como perda de soberania e diminuição do papel estatal. Países em desenvolvimento foram contra o termo por temer a participação ativa de outros países em suas questões internas e retirado quando se referia à questões internacionais.

Os parágrafos referentes à certificação de produtos oriundos da pesca artesanal foram retirados do texto com o apoio da sociedade civil. Foi entendido que a

$\begin{array}{llll}\text { Certificação } & 1 & 2 & 0\end{array}$
atividade seria mais prejudicada do que incentivada por esses arranjos de certificação tradicionais e que novos modelos precisam ser pensados de forma a incluir os contextos da pesca artesanal.

A presença da OMC no texto foi questionada durante as consultas técnicas, permanecendo na seção relativa ao comércio devido à defesa da Argentina.

OMC Comércio internacional

1

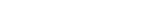
Contrariamente, o texto mostra a necessidade da pesca artesanal em relação aos impactos do comércio internacional (art.7.6) e de levar em consideração os impactos que o comércio pode causar ao ambiente, cultura dos pescadores(as), modo de vida e segurança alimentar (art. 7.7).

Países como a Argentina entenderam o termo economia informal como geradora de atividades ilegais. A União Européia fez proposta apoiada pela Argentina e Chile com vistas a inserir a economia informal da pesca na formalidade, rechaçado pelo Irã e países da África oeste, Noruega e do Brasil, o qual fez um discurso no sentido de que não se pode tratar a informalidade como ilegalidade. "Muitos países não tem condições financeiras de legalizar os pescadores, eles estão informais, mas não infringem nenhuma lei". Os Estados Unidos acataram proposta da Noruega de inserir a palavra setor para clarificar que se tratava apenas da pesca. A sociedade civil justificou que economia informal é bem definida na Organização para Cooperação e Desenvolvimento Econômico (OCDE) e organização Internacional do Trabalho (OIT). Incluiram setor informal separadamente em um parágrafo.

$\mathrm{O}$ termo não foi aceito e trocado por consulta às comunidades. Esse termo é oriundo da Declaração das Nações Unidas sobre os Direitos dos Povos Indígenas. Apenas a participação livre, prévia e informada está citada como princípio das Diretrizes.

Os EUA (apoiados pelo Canadá) modificaram o termo padrões internacionais de direitos humanos por leis internacionais de direitos humanos, o que exclui compromissos voluntários assumidos pelos países no âmbito das Nações Unidas. Este foi citado nos princípios e no texto quando acompanhado de instrumentos especificados. 
Situações de ocupação
0

0

0
Implementação e monitoramento

Essas situações são representadas pela ocupação armada de países e a não permissão de acesso ao mar para os pescadores(as). O texto foi inserido durante a segunda consulta técnica pela Mauritânea diante de lobby da sociedade civil. Foi gerado um grande imbróglio entre Mauritânia e Irã, de um lado, e Canadá e Estados Unidos do outro. A maioria dos países desconhecia o uso desse texto. A solução foi a substituição do termo por "conflito armado" em uma nova redação proposta pela delegação americana. O rascunho zero não foi aprovado nessa consulta e o parágrafo referente ao assunto foi levado à reunião do COFI em aberto: 6.18. [Todas as partes devem proteger os direitos humanos e a dignidade das partes interessadas da pesca de pequena escala em situações de ocupação que lhes permitam dar continuidade a seus modos de vida tradicionais, ter acesso a pesqueiros costumeiros e preservar sua cultura e modo de vida. Deve ser facilitada sua participação efetiva em processos de decisão sobre os assuntos que os afetem.]

O texto sobre monitoramento não foi aceito devido a natureza voluntária das Diretrizes. Essa seção foi enfraquecida também por questões relativas à implementação que foram sempre relacionadas às circunstâncias e prioridades nacionais. Um parágrafo que se referia aos direitos humanos (13.2) foi totalmente retirado. A Argentina, Equador, Chile e os EUA foram os principais países contrários. A principal reação foi em relação à necessidade de se documentar a real contribuição da pesca artesanal por entenderem que existia a conotação de obrigatoriedade na implementação. A Comunidade Europeia sugeriu a inserção do termo "contribuição verdadeira da pesca de pequena escala ao manejo sustentável dos recursos", o que reduziu o teor da proposta ao uso dos recursos. Os últimos quatro parágrafos do documento foram eliminados e a responsabilidade de monitoramento transferida ao COFI com apoio de todos os países.

\begin{tabular}{|c|c|c|c|c|}
\hline $\mathrm{Cu}$ & 21 & 12 & 12 & $\begin{array}{l}\text { O termo "cultural" sofreu resistência por parte de } \\
\text { vários países, principalmente o Canadá. }\end{array}$ \\
\hline
\end{tabular}
Governos resistiram em tratar impactos causados pelo homem na mesma medida dos naturais. A Argentina buscou inserir o princípio das responsabilidades comuns mas diferenciadas, trazido pela Convenção de Mudança Climática, com resistência dos americanos, levando o tema para o final das negociações. Houve substituição pelo documento da Rio +20 .

Termo utilizado em substituição à situações que se referiam com muita ênfase às questões de direitos humanos. O conceito foi utilizado para substituir o termo governança.

A proposta de um parágrafo falando da necessidade de ética na pesquisa em comunidades de pescadores artesanais foi inserida por meio da sociedade civil, não constava inicialmente nos textos rascunhos, porém não foi aceita pelos países.

Termo rechaçado na primeira consulta técnica, foi

\begin{tabular}{|c|c|c|c|c|}
\hline $\begin{array}{l}\text { Grupos } \\
\text { marginalizados e } \\
\text { vulneráveis }\end{array}$ & 1 & 26 & 17 & $\begin{array}{l}\text { Termo rechaçado na primeira consulta técnica, foi } \\
\text { acatado durante a segunda consulta nas frases em que } \\
\text { estavam citados. }\end{array}$ \\
\hline
\end{tabular}


Brasil propôs parágrafo sobre necessidade de consentimento, consulta e estudos de impacto para projetos que impactem a pesca artesanal. O termo consentimento foi rechaçado.(5.10) $\mathrm{O}$ texto final

Impactos negativos sobre a pesca

artesanal
0

0 abordou a consulta às comunidades: estados e outros devem, antes à implantação de projetos de desenvolvimento de larga escala com impacto às comunidades pesqueiras, considerar impactos sociais, econômicos e ambientais (estudos de impactos), e assegurar consultas efetivas e significativas com essas comunidades, de acordo com a legislação nacional.

Questões de prisões de pescadores que ultrapassam os limites de um país e entram nos limites de outro foram discutidas, pois levam a prisões. $O$ consenso não foi atingido e a proposta foi retirada do texto. Bangladesh solicitou a inserção de uma nota sobre o assunto no Relatório final. Baseado na segurança nacional o Chile inseriu a frase "de acordo com as leis nacionais" em diversos momentos.

A pesquisa é co-responsável pelo reconhecimento da pesca artesanal. Paralelo à pressão realizada pelos movimentos sociais a pesquisa redirecionou seus objetivos, incluindo questões como pobreza (Jentoft \& Onyango, 2010, Béné et al., 2016, Prestrelo et al.,2016), marginalização (Ratner et al., 2014) e seguridade alimentar (Mcclanahan et al.., 2015) aos tradicionais estudos para gestão dos estoques pesqueiros (Beverton \& Holt, 1957, Duarte-Neto et al., 2008, Lessa \& Santana, 2016). Em 2010 foi realizado, também em Bankok, o 1. ${ }^{\circ}$ Congresso Mundial de Pesca Artesanal que consolidou a visão interdisciplinar da matéria entre os pesquisadores.

Apesar de algumas imprecisões, o documento representa o consenso entre estados que legitimaram a importância da pesca e das comunidades de pesca artesanal, se constituindo em um paradigma alternativo de desenvolvimento que se aproxima de um discurso mais progressista (Trapman, 2014).

\section{CONSIDERAÇÕES FINAIS}

As Diretrizes da Pesca Artesanal traduzem uma demanda antiga do setor. É um documento que reconhece sua importância e mostra que a pesca artesanal precisa ser tratada dentro do contexto maior das economias locais e nacionais. O problema da pesca não pode ser resolvido apenas pela pesca A maior conclusão a ser tirada do documento é: garantia ao território, saúde, educação, segurança do trabalho e resolução de conflitos com outras atividades estão além da gestão da própria atividade pesqueira.

As negociações em torno das Diretrizes não terminaram com sua adoção na reunião do COFI da FAO. O difícil andamento das negociações apenas indicou que sua implementação demandará esforços, onde mudanças de paradigmas serão necessárias, principalmente no que tange a abordagem sistêmica e ampla do documento. Mudanças legais também são necessárias e já estão em curso em alguns países como a África do Sul, Cambodia (Jentoft, 2014) e Costa Rica (Rivera, 2016). O papel da sociedade civil foi muito importante na geração desse novo conceito e deverá ser mais importante ainda na busca por sua implementação. É importante que os consumidores também sejam incorporados ao processo. O conceito de governança adaptativa e iterativa pode ser utilizado na tenta- 
tiva de abarcar o dinamismo existente na pesca artesanal (Kooiman et al., 2005). Além disso, é necessário que a pesca artesanal seja objeto de estudos interdisciplinares na tentativa de abranger todo o conteúdo exposto no documento aqui analisado.

Também se faz necessário a geração de dados e acompanhamento da implementação do documento, premissa básica para uma boa governança. Mundialmente os dados oriundos dessas pescarias não são coletados separadamente da pesca industrial (Pauly \& Charles, 2015), isso deve ser cobrado pela FAO de seus países membros. No Brasil, o renascimento da estatística pesqueira é um dos primeiros passos a serem dados, incorporando separadamente dados de produção para a pesca artesanal, além de especificidades como gênero, idade e migração de pescadores(as), por exemplo. O país tem a chance de iniciar um novo ciclo no setor, reconhecendo e valorizando o importante papel da pesca na sociedade, inserindo os direitos humanos no contexto da governança da pesca artesanal.

\section{REFERÊNCIAS}

Béné, C.; Arthur, R.; Norbury, H.; Allison, E.H.; Beveridge, M.; Bush, S.; Campling, L.; Leschen, W.; Little, D.; Squires, D.; Thilsted, S.H.; Troell, M.; Williams, M. Contribution of Fisheries and Aquaculture to Food Security and Poverty Reduction: Assessing the Current Evidence. World Dev., v. 79, p. 177-196, 2016.

Beverton, R.J.H.; Holt, S.J. On the Dynamics of Exploited Fish Populations. Fisheries Investigations Series 2: Sea Fisheries. London: Ministry of Agriculture. 1957, p. 533.

Duarte-Neto, P.; Lessa, R.; Stosic, B.; Morize, E. The use of sagittal otoliths in discriminating stocks of common dolphinfish (Coryphaena hippurus) off northeastern Brazil using multishape descriptors. ICES J Mar Sci., v. 65, n. 7, p. 1144-1152, 2008.

FAO. Code of Conduct for Responsible Fisheries. Food and Agriculture Organization of the United Nations. 41 p. Rome, 1995.

FAO. Voluntary Guidelines for Securing Sustainable Small-Scale Fisheries. Food and Agriculture Organization of the United Nations. 34 p., Rome, 2015a.

FAO. A Review of Women's Access To Fish in Small-Scale Fisheries. Food and Agriculture Organization of the United Nations. 36 p., Rome, 2015b.

FAO. The state of world fisheries and aquaculture. Contributing to food security and nutrition for all. 200 p., Rome, 2016.

Jentoft, S. Walking the talk: implementing the international voluntary guidelines for securing sustainable small-scale fisheries. Maritime Studies, v. 13, n. 1, p. 16, 2014.

Jentoft, S.; Chuenpagdee, R. Fisheries and coastal governance as a wicked problem. Mar. Policy, v. 33, n. 4, p. 553-560, 2009.

Jentoft, S.; Onyango, P. Freedom and poverty in the fishery commons. Inter. J. Commons, v. 4, n. 1, p. 345-366, 2010.

Kooiman, J.; Bavinck, M. Fish for life: Interactive governance for fisheries. Ocean Coast Manag., v. 50, n. 7, p. 590-596, 2005.

Lessa, R.; Santana, F.M. Growth of the dolphinfish Coryphaena hippurus from north-eastern Brazil with an appraisal of the efficacy of scales and otoliths for ageing. J. Fish Biol., v. 89, n. 1, p. 977-989, 2016. 
Mathew, S. Shepherding Small Scale Fisheries. Samudra, v. 68, p. 9-16, 2014.

McClanahan, T.; Allison, E. H.; Cinner, J. E. Managing fisheries for human and food security. Fish Fish, v. 16, n. 1, p. 78-103, 2015.

Pauly, D.; Charles, A. Counting on small-scale fisheries. Science, v. 347, n. 6219, p. 242-243. New York, 2015.

Prestelo, L.; Vianna, E. M.; Vianna, M. Identifying multiple-use conflicts prior to marine spatial planning: a case study of a multi-legislative estuary in Brazil. Mar. Policy, v. 67, p. 83-93, 2016.

Ratner, B. D.; Åsgard, B.; Allison, E. H. Fishing for justice: Human rights, development, and fisheries sector reform. Glob. Environ. Change, v. 27, n. 1, p. 120-130, 2014.

Rivera, V.S. Sailing from a good port. Samudra, v. 73, p. 7-9, 2016.

Song, A. M. Human dignity: A fundamental guiding value for a human rights approach to fisheries? Mar. Policy, v. 61, p. 164-170, 2015.

Trapman, B. Contestation of the Corporate Food Regime in FAO: The Case of the Small Scale Fisheries Guidelines. Dissertação de Mestrado (Political Science - International relations), University of Amsterdam. 87 p. Amsterdam, 2014. 